\title{
EFFECT OF Hf AND B ON TRANSVERSE AND LONGITUDINAL CREEP OF A Re-CONTAINING NICKEL-BASE BICRYSTAL SUPERALLOY
}

\author{
Y.S. Zhao ${ }^{1,2}$, J. Zhang 2 , Y.S. Luo $^{2}$, G. Sha ${ }^{3}$, D.Z. Tang ${ }^{2}$, Q. Feng ${ }^{1}$ \\ 1. State Key Laboratory for Advanced Metals and Materials, University of Science and Technology Beijing, Beijing 100083, China \\ 2. Science and Technology on Advanced High Temperature Structural Materials Laboratory, Beijing Institute of Aeronautical Materials, \\ Beijing 100095, China \\ 3. Herbert Gleiter Institute of Nanoscience, Nanjing University of Science and Technology, Nanjing 210094, China
}

Keywords: DD11 superalloy, Hf, B, grain boundaries, segregation behaviors, creep properties

\begin{abstract}
Hf and B have been added into single crystal superalloys as micro-alloying elements to strengthen low angle grain boundaries. However, systematic investigations and quantitative characterizations of the microstructural evolution of grain boundaries in superalloys with different $\mathrm{Hf}$ and $\mathrm{B}$ additions are little reported. In this study, a double-seed solidification technique was used to produce nickel-base DD11 superalloy with two levels of misorientation $\left(5^{\circ}\right.$ and $\left.20^{\circ}\right)$. A detailed characterization of the misorientation related microstructures at the grain boundary (GB) in three bicrystal superalloys has been carried out; and the elemental distribution at the GB has been analyzed by using Auger electron spectroscopy (AES), time of flight secondary ion mass spectrometry (TOF SIMS) and atom probe tomography (APT) techniques. It was found that the bicrystals integrated well with each other although, in all three alloys, an almost continuous thin layer with bright contrast was seen at the low angle grain boundary (LAB). Cellular recrystallization microstructures along the high angle grain boundary (HAB) were found in the Hf and B free alloy, but they were significantly suppressed with the addition of either Hf or a joint addition of $\mathrm{Hf}$ and $\mathrm{B}$. There was no obvious segregation of Hf, but the segregation of B to HAB was clearly identified by all the analyses using TOF SIMS, AES and APT. The creep properties were closely related to that of the matrix in alloys with LAB, but they were influenced remarkably by secondary precipitates and GB segregation in alloys with HAB. The additions of $\mathrm{Hf}$ and $\mathrm{B}$ together improved the transverse and longitudinal creep rupture lives in the alloy with HAB significantly under the conditions of $1100{ }^{\circ} \mathrm{C} / 130 \mathrm{MPa}$, $980{ }^{\circ} \mathrm{C} / 250 \mathrm{MPa}$ and $760{ }^{\circ} \mathrm{C} / 785 \mathrm{MPa}$. This study is helpful to better understand the role of $\mathrm{Hf}$ and $\mathrm{B}$ in strengthening GB and to optimize Hf and B additions in DD11 superalloy.
\end{abstract}

\section{Introduction}

Single crystal (SX) technology has been successfully utilized in aero-engine and gas turbine industry [1]. However, low angle or high angle grain boundary (LAB or HAB) defects are inevitably generated during directional solidification of turbine blades due to the failure of grain selection or the nucleation of spurious grains around areas of rapidly changing cross-sections such as platforms and shrouds [2]. Turbine blades are expected to withstand aggressive service conditions, such as high temperature, complex stress combined with an oxidation environment [1], thus, the deformation induced by creep is one of the dominant failure modes in turbine blades $[1,2]$. Therefore, the existence of grain boundary (GB) defects will lead to inhomogeneous deformation, accelerating the formation of creep cracks and thus the creep strain rate. As a result, the mechanical properties of SX superalloys could be dramatically degraded by grain boundaries, especially when the misorientation of the grain boundaries exceeds some critical value [3].

It is generally believed that LABs may not degrade high temperature mechanical properties, but HABs have a strong detrimental effect, particularly on creep properties [3, 4]. From an engineering point of view, the presence of grain boundaries must be tolerated to maintain the investment castings as an economically viable production technique. Therefore, some SX turbine airfoils are scrapped due to the formation of HABs, resulting in lower casting yield. Therefore, improving GB tolerance of SX superalloys is still an important and challenging task for material scientists. Previous works have reported, the misorientation tolerance of most unmodified SX superalloys was less than or equal to about $10^{\circ}$, for example, $6^{\circ}$ for René N SX superalloy [4], $6^{\circ}$ for CM 186LC SX superalloy [5], and $10^{\circ}$ for PWA 1483 SX superalloy [6]. Significant improvements in the tolerance of transverse creep properties to high angle grain boundaries with minor alloying additions of $\mathrm{C}, \mathrm{B}$ and $\mathrm{Hf}$ have been found in some SX superalloys [4, 6, 7]. Ross and O'Hara [4], in their study of the alloy René N4, suggested that the additions of minor alloying elements enhanced the GB tolerance to $12^{\circ}$ misorientation. However, the exact mechanisms associated with the increased casting tolerance are not well understood. Chen et al. [7] explained that the higher concentration of $\mathrm{C}$ caused a larger density of carbides along on the grain boundaries, which were responsible for the enhanced creep performance. However, up to now, there have been few reports about the individual and interactive roles of $\mathrm{Hf}$ and $\mathrm{B}$ additions on the creep properties of grain boundaries in SX superalloys.

For experimental convenience, bicrystalline slabs were usually used to investigate grain boundaries in SX superalloys. Most previous studies have been conducted on the effects of transverse grain boundaries on mechanical properties, as these are the most serious grain boundary defects in SX superalloys. However, the principal direction of centrifugal stress in turbine blades is parallel to the crystal growth direction, and the creep behaviors of longitudinal grain boundaries may be more close to the actual operating conditions of turbine blades. Therefore, in order to better understand creep behaviors of SX superalloys containing GB defects and the effect of minor alloying additions, the study of longitudinal creep behaviors was thought to be of equal importance.

The aim of the present work is to investigate the effects of $\mathrm{Hf}$ and $B$ additions on the transverse and longitudinal creep properties in three alloys containing different misorientation angles in almost 
Table I. Measured chemical compositions of three experimental superalloys (wt.\%).

\begin{tabular}{|c|c|c|c|c|c|c|c|c|c|c|c|c|}
\hline Alloy & $\mathrm{Ni}$ & $\mathrm{Al}$ & $\mathrm{Cr}$ & $\mathrm{Ta}$ & $\mathrm{W}$ & $\mathrm{Co}$ & $\mathrm{Mo}$ & $\mathrm{Re}$ & $\mathrm{C}$ & $\mathrm{Nb}$ & $\mathrm{Hf}$ & $\mathrm{B}$ \\
\hline Base alloy & $\mathrm{Bal}$. & 5.52 & 4.26 & 6.50 & 6.87 & 8.04 & 2.04 & 2.96 & 0.005 & 0.49 & $<0.05$ & $<0.005$ \\
\hline Alloy Hf & $\mathrm{Bal}$. & 5.55 & 4.18 & 6.52 & 6.77 & 7.92 & 2.02 & 2.92 & 0.009 & 0.49 & 0.40 & $<0.005$ \\
\hline Alloy HfB & Bal. & 5.46 & 4.21 & 6.60 & 6.87 & 8.09 & 2.08 & 2.99 & 0.008 & 0.50 & 0.43 & 0.01 \\
\hline
\end{tabular}

the whole service temperature range. Relationships among Hf and $\mathrm{B}$ additions, GB microstructural evolution characteristics, segregation behaviors of alloying elements, transverse and longitudinal creep properties have been analyzed. This study could pave the way for the improved creep resistance of SX superalloys with high angle boundaries through minor alloying additions.

\section{Experimental procedures}

The current investigated alloy is a second generation SX superalloy DD11, which was developed by Beijing Institute of Aeronautical Materials (BIAM), China. It is being considered as a promising candidate for the application of turbine blades in aircraft engines with the normal service temperature of $1060{ }^{\circ} \mathrm{C} \sim 1100{ }^{\circ} \mathrm{C}$ due to its excellent balanced performance of creep strength, oxidation, hot corrosion resistance and castability [8].

Measured chemical compositions of three experimental alloys including the base alloy (DD11) with Hf and B free are listed in Table I. Alloy Hf contains 0.40 wt.\% Hf while alloy HfB contains 0.43 wt. $\%$ Hf and 0.01 wt. $\%$ B. The bicrystal slabs with the misorientation angles of about $5^{\circ}$ and $20^{\circ}$ were prepared for all three experimental alloys, and they were named as low angle grain boundary (LAB) and high angle grain boundary (HAB) in this study, respectively. Double-seed moulds were used by rotating the seeds in the X-Y plane to achieve a single GB with a specific misorientation and produce directional solidification $(\mathrm{Z}$ direction) along the $<001>$ orientation as shown in Fig. 1a. Bicrystal slabs of each alloy were directionally solidified by using conventional Bridgman casting technique with the withdrawn rate of $3 \mathrm{~mm} / \mathrm{min}$. Inverse pole figure (IPF) maps extracted from electron backscatter diffraction (EBSD) maps across grain boundaries were used to determine the misorientation angles. Bicrystal slabs of base alloy and alloy Hf were solution heat treated at $1320{ }^{\circ} \mathrm{C}$ for $4 \mathrm{~h}$ (air-cooling), but bicrystal slabs of alloy $\mathrm{HfB}$ were solution heat treated at $1310^{\circ} \mathrm{C}$ for $6 \mathrm{~h}$ (air-cooling) due to the lower incipient melting temperature with the addition of $\mathrm{B}$. The process of solution heat treatments were followed by a stage of primary ageing at $1130{ }^{\circ} \mathrm{C}$ for $4 \mathrm{~h}$ and a subsequent second stage of ageing at $870{ }^{\circ} \mathrm{C}$ for 32 $\mathrm{h}$, both followed by air-cooling. Figs. $2 \mathrm{a}$ and $2 \mathrm{~b}$ present the typical cross-sectional optical images perpendicular to $<001>$ orientation around GB region of bicrystals in the base alloy with $\mathrm{LAB}$ and HAB. A dashed line indicates the location of the bicrystal boundary and $\mathrm{HAB}$ exhibited higher amplitude of waviness, compared to LAB. The grain boundary distributed in the interdendritic region and misorientation measurements by using secondary dendrite arms in each grain were consistent with the results of inverse pole figure (IPF) maps.

The creep tests were carried out at $1100{ }^{\circ} \mathrm{C} / 130 \mathrm{MPa}, 980{ }^{\circ} \mathrm{C} / 250$ $\mathrm{MPa}$ and $760{ }^{\circ} \mathrm{C} / 785 \mathrm{MPa}$, and the loading direction was perpendicular to the bicrystal boundary. Meanwhile, the creep

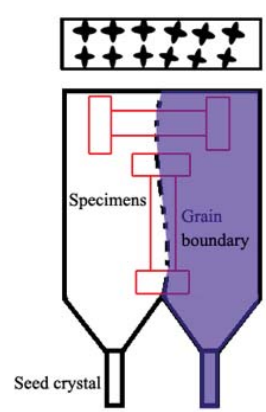

(a)

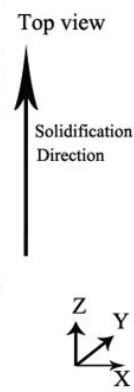

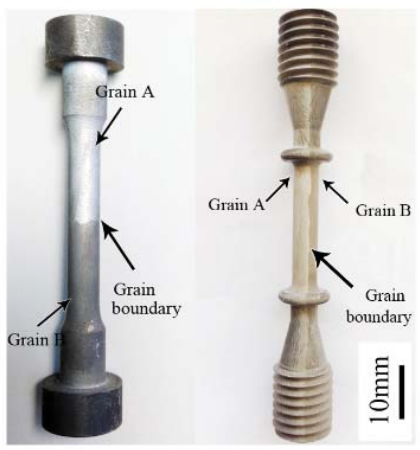

(b)
Fig. 1 Sketch of the bicrystal slab casting (a) and the transverse and longitudinal (b) creep testing specimens after macroetching.

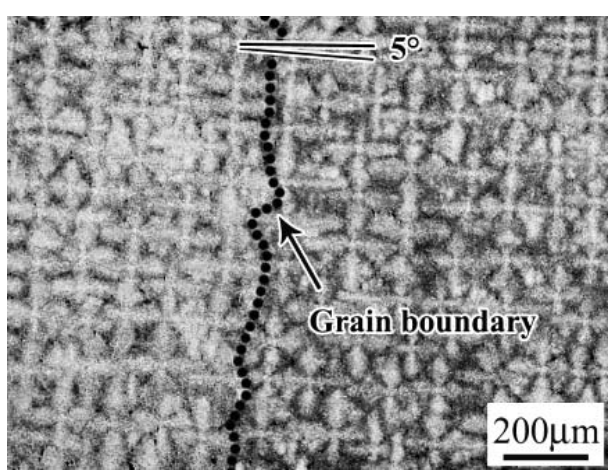

(a)

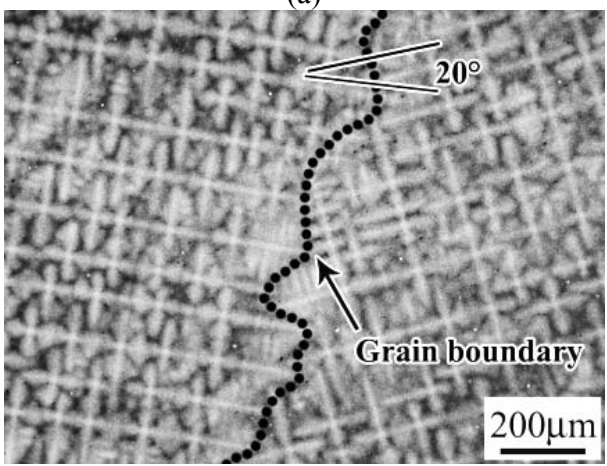

(b)

Fig. 2 Optical images of GB region in bicrystals of the base alloy with LAB (a) and HAB (b) after the full heat treatment.

tests with the loading direction longitudinal to the bicrystal boundary were also employed in this investigation at $1100{ }^{\circ} \mathrm{C} / 130 \mathrm{MPa}$. The transverse and longitudinal creep testing specimens after macroetching are shown in Fig. $1 \mathrm{~b}$.

The cross-sectional microstructures of experimental alloys perpendicular to $<001>$ orientation were examined under different conditions. The creep-ruptured samples were sectioned 


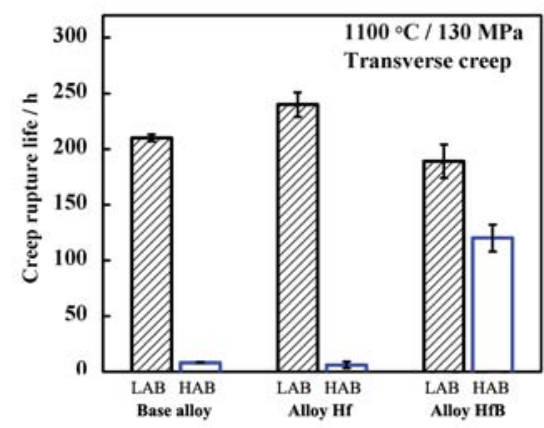

(a)

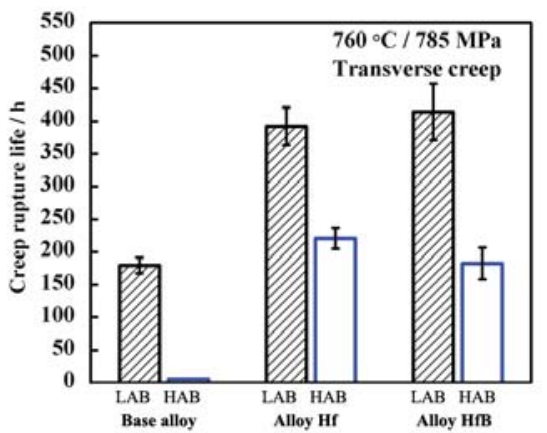

(c)

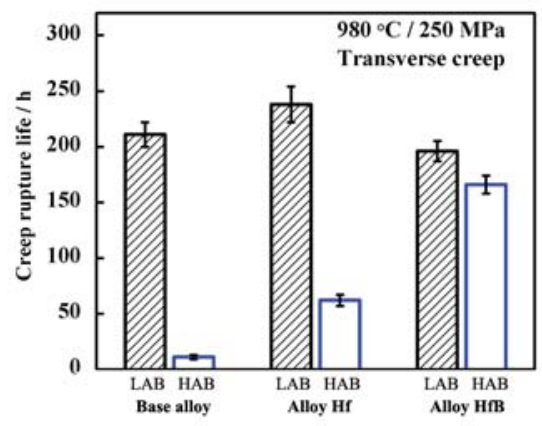

(b)

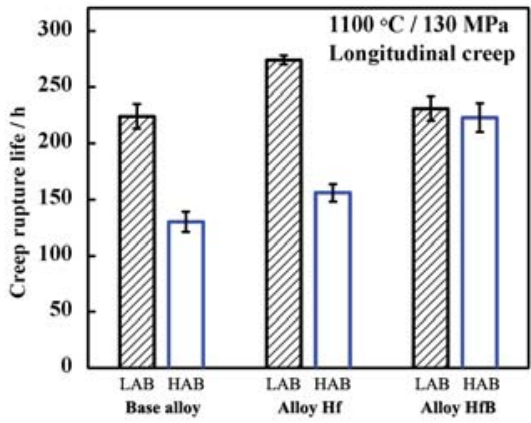

(d)

Fig. 3 Creep properties of three experimental alloys with LAB and HAB under different creep conditions: (a) transverse, $1100{ }^{\circ} \mathrm{C} / 130$ $\mathrm{MPa}$, (b) transverse, $980{ }^{\circ} \mathrm{C} / 250 \mathrm{MPa}$, (c) transverse, $760{ }^{\circ} \mathrm{C} / 785 \mathrm{MPa}$ and (d) longitudinal, $1100{ }^{\circ} \mathrm{C} / 130 \mathrm{MPa}$.

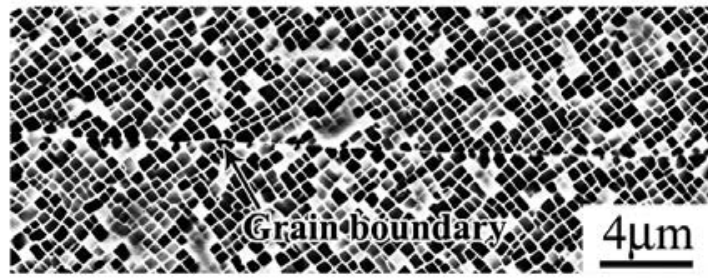

(a)

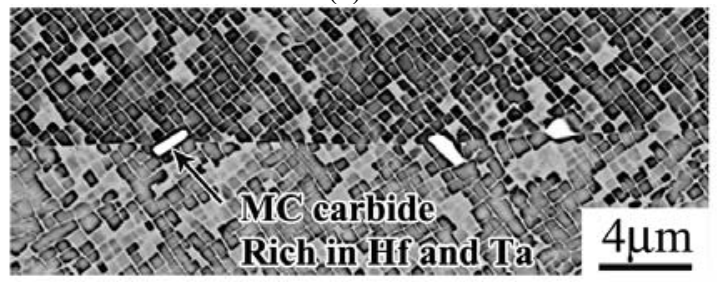

(c)

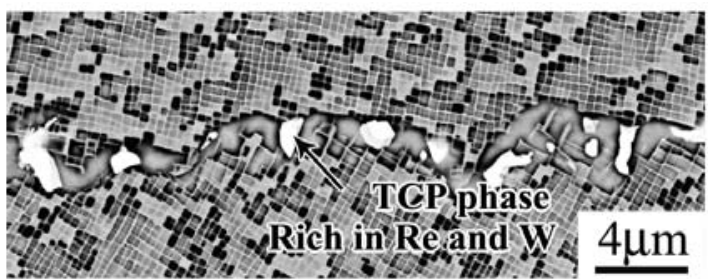

(b)

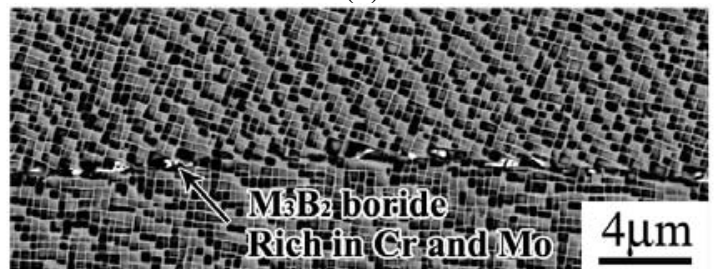

(d)

Fig. 4 SEM images of GB microstructures in bicrystals of the base alloy with LAB (a) and HAB (b), alloy Hf with HAB (c) and alloy HfB with $\mathrm{HAB}(\mathrm{d})$.

Table II. Main alloying compositions of three types of precipitates along the grain boundaries using SEM-EDS in different alloys after the full heat treatment (at.\%).

\begin{tabular}{|c|c|c|c|c|c|c|c|c|c|}
\hline Compositions & $\mathrm{Cr}$ & $\mathrm{Mo}$ & $\mathrm{W}$ & $\mathrm{Re}$ & $\mathrm{Co}$ & $\mathrm{Ni}$ & $\mathrm{Hf}$ & $\mathrm{Ta}$ & $\mathrm{Nb}$ \\
\hline $\begin{array}{c}\text { TCP phase } \\
\text { (Base alloy) }\end{array}$ & 10.4 & 10.9 & 19.5 & 15.0 & 15.6 & 28.6 & 0 & 0 & 0 \\
\hline $\begin{array}{c}\text { MC carbide } \\
\text { (Alloy Hf) }\end{array}$ & 0 & 0 & 0 & 0 & 2.2 & 9.0 & 39.9 & 27.1 & 21.8 \\
\hline $\begin{array}{c}\mathrm{M}_{3} \mathrm{~B}_{2} \text { phase } \\
\text { (Alloy HfB) }\end{array}$ & 17.8 & 32.9 & 18.5 & 4.4 & 6.2 & 12.5 & 0 & 7.7 & 0 \\
\hline
\end{tabular}

*Note: Averages of four measurements, carbon and boron are not included due to the inaccurate measurement by SEM-EDS. 
parallel to the load axis. Samples were prepared using the standard metallographic techniques and etched in a solution of $33 \%$ hydrochloric acid, 33\% acetic acid, 33\% water and 1\% hydrofluoric acid. Microstructural examination and fractographic studies were performed using a ZEISS Axio optical microscope (OM) and a ZEISS SUPRA 55 field-emission scanning electron microscope (FE-SEM). The GB secondary phases are quantitatively characterized as linear density, which is defined by the $l_{c} / l$ ratio, where $l_{c}$ is the length of the GB that is filled withsecondary phases, and $l$ is the length of whole GB. To obtain statistically significant results, three to five images were used in each alloy.

Interfacial segregation of alloy $\mathrm{HfB}$ with $\mathrm{HAB}$ was analyzed using Auger electron spectroscopy (AES). Specimens were impacted at liquid nitrogen temperatures and immediately placed into the vacuum chamber of a PHI 700 Scanning Auger Nanoprobe for the composition analyses of the fracture surface under an acceleration voltage of $10 \mathrm{kV}$. Time of flight secondary ion mass spectrometry (TOF SIMS) was also used to characterize the chemistry in GB regions. Site-specific samples were prepared for atom probe tomography (APT) analyses by using a ZEISS AURIGA focused ion beam (FIB). Whereas the atom probe analyses were performed in a Cameca LEAP 4000X Si instrument operating in a UV laser pulsing mode with a pulse rate of $200 \mathrm{kHz}$ and at a laser energy of $40 \mathrm{pJ}$. Reconstruction was carried out by using a commercial software Cameca IVAS ${ }^{\circ}$ 3.6.8 following the protocol introduced by Geiser et al. [9].

\section{Results}

\section{$\underline{\text { Creep properties }}$}

Figs. $3 \mathrm{a} \sim 3 \mathrm{c}$ show the transverse creep properties at $1100{ }^{\circ} \mathrm{C} / 130$ $\mathrm{MPa}, 980{ }^{\circ} \mathrm{C} / 250 \mathrm{MPa}$ and $760{ }^{\circ} \mathrm{C} / 785 \mathrm{MPa}$ in three alloys with $\mathrm{LAB}$ and $\mathrm{HAB}$, respectively. Fig. $3 \mathrm{~d}$ shows the longitudinal creep properties at $1100{ }^{\circ} \mathrm{C} / 130 \mathrm{MPa}$ in three alloys with $\mathrm{LAB}$ and $\mathrm{HAB}$. It is obvious that the creep rupture lives of the bicrystal superalloys with $\mathrm{LAB}$ reached the maximum by $\mathrm{Hf}$ addition and the minimum by $\mathrm{Hf}$ and $\mathrm{B}$ additions together among three experimental alloys (Figs. 3a, 3b and 3d), except that under $760{ }^{\circ} \mathrm{C} / 785 \mathrm{MPa}$ (Fig. 3c). For a fixed alloy, the transverse creep rupture life of bicrystal superalloy with $\mathrm{HAB}$ was significantly less than that with $\mathrm{LAB}$, while its longitudinal creep rupture life with $\mathrm{HAB}$ was close to that with $\mathrm{LAB}$. The creep rupture life of alloy Hf with $\mathrm{HAB}$ was higher than that of the base alloy with $\mathrm{HAB}$, while the bicrystal superalloy with $\mathrm{HAB}$ improved the creep rupture life significantly by both $\mathrm{Hf}$ and $\mathrm{B}$ additions. In addition, it should be noted that the creep rupture life in alloy HfB with $\mathrm{HAB}$ was slightly less than that of alloy $\mathrm{Hf}$ at $760{ }^{\circ} \mathrm{C} / 785 \mathrm{MPa}$ (Fig. 3c). Through the comparison of creep properties in Fig. 3, the base alloy and alloy Hf with HAB were equipped with poor creep rupture lives. However, the alloy HfB with $\mathrm{HAB}$ had the best balanced creep rupture lives in the temperature range of $760{ }^{\circ} \mathrm{C}$ and $1100{ }^{\circ} \mathrm{C}$. These data may pave the way for creep resistance improvement of SX superalloys with high angle boundaries through minor $\mathrm{Hf}$ and $\mathrm{B}$ additions.

\section{Initial microstructure near the GB region}

Fig. 4 presents the typical microstructures around the GB regions of three experimental alloys after the full heat treatment. The bicrystals with LAB integrated well with each other through an almost continuous thin layer with bright contrast in all three alloys. Meanwhile, there were almost no secondary precipitates along the LABs, and one example is shown in Fig. 4a. But, the secondary precipitates were observed along the HABs and the morphology was significantly different (Figs. $4 b \sim 4 d$ ) in all three alloys. The cellular recrystallization microstructure was observed along the GB, and TCP phases were identified to precipitate in certain cellular recrystallized aggregates of the base alloy (Fig. 4b). The average width of the cellular recrystallized microstructure was about $2.5 \mu \mathrm{m}$. Nevertheless, the cellular recrystallization was not found in alloy $\mathrm{Hf}$ and alloy $\mathrm{HfB}$ with HAB (Figs. $4 \mathrm{c}$ and $4 \mathrm{~d}$ ). It indicates that minor Hf addition play an important role in suppressing the occurrence of cellular recrystallization along the $\mathrm{HAB}$, but the effect of minor $\mathrm{B}$ addition on cellular recrystallization requires further investigation. Meanwhile, there were a small quantity of discontinuous blocky MC carbides along the HAB in alloy Hf (Fig. 4c). The size of MC carbides on the GB in alloy Hf was about $1 \mu \mathrm{m} \sim 2 \mu \mathrm{m}$. Meanwhile, a distinctive amount of very fine discrete $\mathrm{M}_{3} \mathrm{~B}_{2}$ borides with the size of about $0.3 \mu \mathrm{m} \sim 1 \mu \mathrm{m}$ precipitated along the HAB of alloy HfB (Fig. 4d). Table II summarizes the compositions of three types of precipitates on the grain boundaries as obtained by SEM-EDS analyses. It is indicated that TCP phase formers Re, W, Mo and $\mathrm{Cr}$ were significantly enriched in the TCP phase. The elements Hf, Ta and Nb were significantly enriched in the MC carbides, while $\mathrm{Cr}, \mathrm{Mo}, \mathrm{W}$ and Ta were enriched in the $\mathrm{M}_{3} \mathrm{~B}_{2}$ borides.

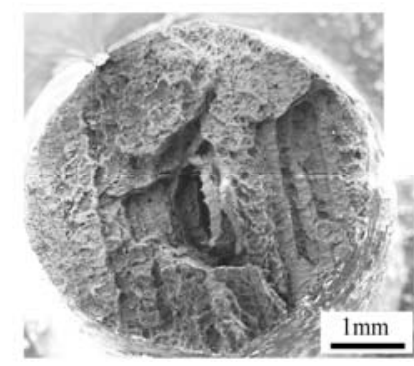

(a)

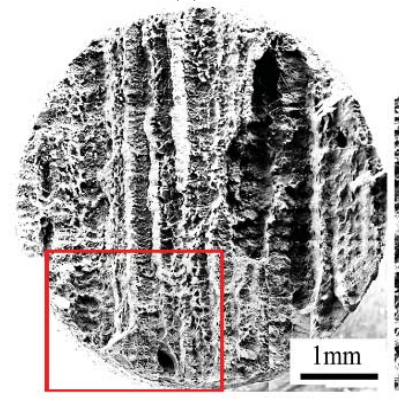

(c)

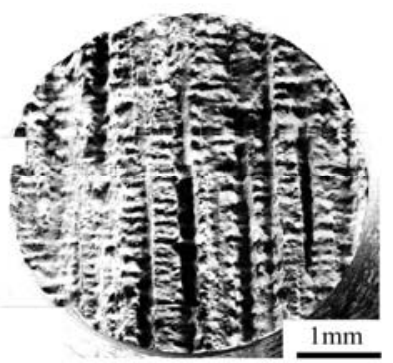

(b)
Fig. 5 Fracture surfaces of transverse creep-ruptured specimens tested at $1100{ }^{\circ} \mathrm{C} / 130 \mathrm{MPa}$, (a) trans-granular failure of the base alloy with $\mathrm{LAB}$, (b) inter-granular failure of the base alloy with $\mathrm{HAB}$, (c) mixed inter- and trans-granular failure of alloy HfB with $\mathrm{HAB}$, (d) high magnification image of square frame in (c).

\section{$\underline{\text { Transverse creep fractures }}$}

Fig. 5 shows fracture surfaces of transverse creep-ruptured specimens tested at $1100{ }^{\circ} \mathrm{C} / 130 \mathrm{MPa}$. With the stress normal to 


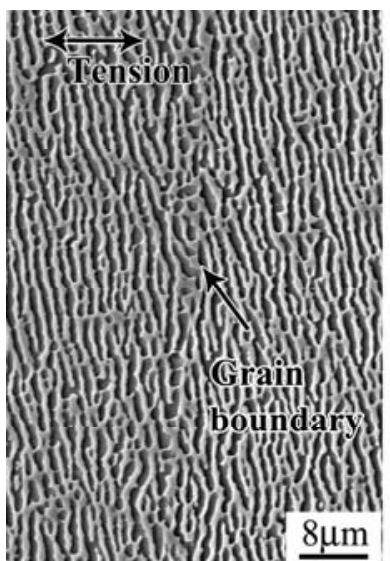

(a)

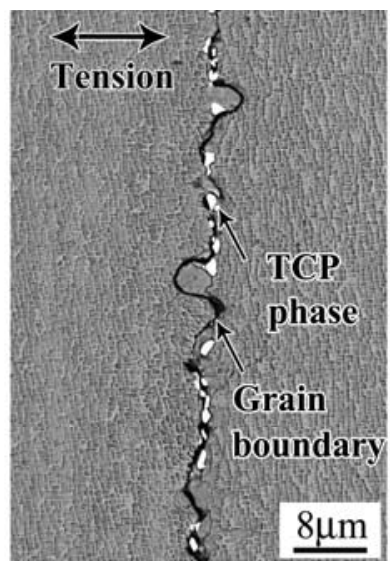

(b)

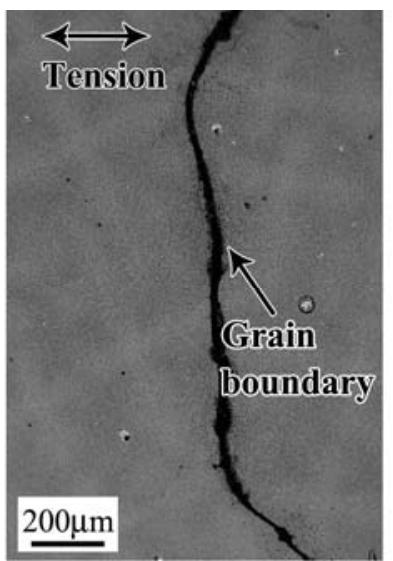

(c)

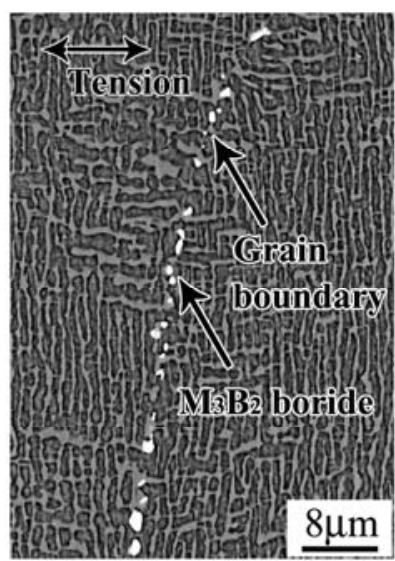

(d)

Fig. 6 Typical microstructures near the GB regions parallel to the stress axis in three alloys after creep-interrupted tests at $1100{ }^{\circ} \mathrm{C} / 130$ $\mathrm{MPa}$, (a) base alloy with LAB, 40 h; (b) base alloy with HAB, 5 h; (c) alloy Hf with HAB, 5 h and (d) alloy HfB with HAB, 40 h.

the bicrystal boundaries, trans-granular failure was observed in all three alloys with $\mathrm{LAB}$, and one example is shown in Fig. 5a. Obvious necking phenomenons were observed, and there were a lot of dimples in the fracture zone of the base alloy with LAB. Intergranular failure without the dimple feature was observed in the base alloy and alloy Hf with $\mathrm{HAB}$, and the smooth fracture surfaces with the dendritic morphology is shown in Fig. $5 b$. However, the mixed feature of inter- and trans-granular failure was dominant in alloy HfB with HAB (Fig. 5c). The obvious dendritic morphology existed, and the fracture characteristics of dimples were also found in the fracture surface of alloy HfB with HAB (Fig. 5d). The transition from the complete inter-granular fracture to mixed failure between alloy $\mathrm{Hf}$ and alloy HfB implies a dramatic enhancement of GB strength with B addition.

\section{Creep-interrupted microstructure}

To investigate the mechanisms of both creep strengthening and fracture of grain boundaries in bicrystal superalloys by the additions of $\mathrm{Hf}$ and $\mathrm{B}$, the creep-interrupted tests with the loading direction perpendicular to the bicrystal boundary were performed for three alloys with both $\mathrm{LAB}$ and $\mathrm{HAB}$. Interrupted tests were carried out after $40 \mathrm{~h}$ in all three alloys with LAB and alloy HfB with $\mathrm{HAB}$, but the interrupted tests were carried out only after 5 $h$ in the base alloy and alloy Hf with HAB due to their short creep rupture lives (about $10 \mathrm{~h}$ ).

Fig. 6 illustrates the typical microstructures near the GB regions parallel to the stress axis in three alloys after the creepinterrupted tests at $1100{ }^{\circ} \mathrm{C} / 130 \mathrm{MPa}$. No secondary cracks were observed along the GB in the base alloy with LAB after creep interruption at $40 \mathrm{~h}$, as shown in Fig. 6a. Smooth transition of the rafting microstructure at the GB occurred in all three alloys with LAB. Fig. $6 \mathrm{~b}$ presents the typical microstructure of creepinterrupted specimens at $5 \mathrm{~h}$ in the base alloy with HAB. Continuous cracks propagated along the interfaces between the matrix and TCP precipitates/large $\gamma^{\prime}$ phase of the cellular recrystallized microstructure along the GB. Fig. 6c shows a continuous crack existed along the GB with limited secondary precipitates after creep interruption at $5 \mathrm{~h}$ in alloy Hf with HAB. However, a complete GB decorated with fine and discrete $\mathrm{M}_{3} \mathrm{~B}_{2}$ borides appeared in alloy HfB with $\mathrm{HAB}$ after the creep test interrupted at $40 \mathrm{~h}$, as shown in Fig. $6 \mathrm{~d}$. The GB borides were again enriched in $\mathrm{Cr}$ and $\mathrm{Mo}$, and their size was in the range of $0.5 \mu \mathrm{m}$ and $2 \mu \mathrm{m}$, significantly larger than that of initial $\mathrm{M}_{3} \mathrm{~B}_{2}$ borides after the full heat treatment (Fig. 4d). The current linear density of GB borides was about $55 \%$, which was also obviously higher than that of GB borides in the initial microstructure. The above microstructural features suggested that a substantial amount of GB borides precipitated and coarsened during the creep.

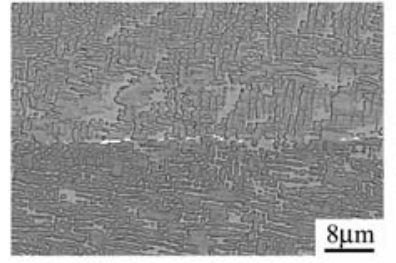

(a)

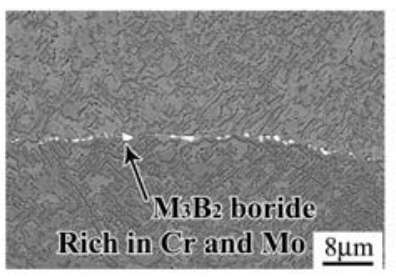

(c)

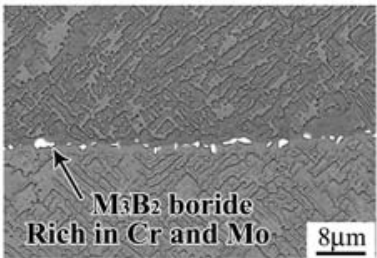

(b)

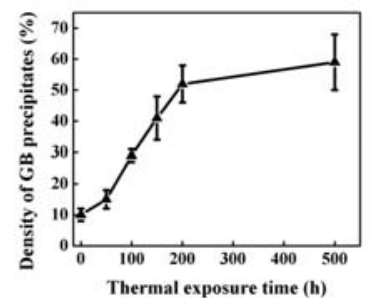

(d)
Fig. 7 Typical microstructural evolution of secondary phases along GB in alloy HfB with HAB after thermal exposure: (a) $1100{ }^{\circ} \mathrm{C} / 50 \mathrm{~h}$; (b) $1100{ }^{\circ} \mathrm{C} / 200 \mathrm{~h}$; (c) $1100{ }^{\circ} \mathrm{C} / 500 \mathrm{~h}$ and (d) the linear density of GB precipitates as a function of thermal exposure time.

\section{Microstructural evolution of GB precipitates during thermal exposure}

To understand the microstructural evolution of precipitates along the HAB in alloy HfB during creep, the thermal exposure simulation experiments were performed at $1100{ }^{\circ} \mathrm{C}$ without the applied creep stress. Figs. $7 \mathrm{a} \sim 7 \mathrm{c}$ show the typical microstructural evolution of secondary precipitates $\left(\mathrm{M}_{3} \mathrm{~B}_{2}\right.$ borides) in alloy $\mathrm{HfB}$ with $\mathrm{HAB}$ after thermal exposure at $1100{ }^{\circ} \mathrm{C}$ for $100 \mathrm{~h}, 200 \mathrm{~h}$ and $500 \mathrm{~h}$, respectively. Small amounts of fine and bright-contrast 
precipitates $\left(f_{l} \sim 15 \%\right)$ were found to exist along the GB (Fig. 7a). Figs. $7 \mathrm{~b}$ and $7 \mathrm{c}$ exhibit that the prolonged thermal exposure time obviously increased the density of bright-contrast precipitates along the GB, and these precipitates coarsened and connected. The composition analyses using SEM-EDS indicated that these bright-contrast phases were enriched in alloying elements $\mathrm{Cr}$ and Mo, which were assumed to be $\mathrm{M}_{3} \mathrm{~B}_{2}$ borides again. For simplicity, Fig. $7 \mathrm{~d}$ summarizes the relationship between the linear density of GB precipitates and exposure time at $1100{ }^{\circ} \mathrm{C}$. It is indicated that the liner density of GB precipitates increased more significantly at the exposure time for the first $200 \mathrm{~h}$, and then appeared to become stable at the exposure time for the next $300 \mathrm{~h}$.

\section{Elemental segregation to GB}

GB segregation of alloying elements is important for understanding GB properties and physical behavior. The combined measurements of TOF SIMS, AES and APT were utilized to investigate and confirm the segregation behaviors of alloying elements in alloy HfB with HAB in this study.
Segregation behaviors of $\mathrm{Hf}$ and $\mathrm{B}$ to grain boundaries were revealed using the mapping mode of TOF SIMS as illustrated in Figs. $8 \mathrm{a}$ and $8 \mathrm{~b}$, respectively. These results suggest that there was no obvious segregation of $\mathrm{Hf}$, while the segregation of $\mathrm{B}$ to $\mathrm{HAB}$ was clearly observed in two forms. First, the partitioning of $\mathrm{B}$ into borides was apparent along the GB; second, B segregation in solid solution form at the HAB was also detected in alloy HfB. A linescan across the GB region without borides in the elemental map by using TOF SIMS shows that the intensity of B along the GB region reached the peak (Fig. 8c), again indicating that $\mathrm{B}$ segregated in solid solution form at the HAB.

Fig. 9a shows the Auger spectrum with different sputtered depth on the GB in alloy HfB with HAB. The Hf segregation to the GB was not detected, but the energy peaks of $B$ and $C$ existed within all sputtered depth. Fig. 9b shows the corresponding B and C concentrations as a function of the sputtered depth. Compared with the slight decrease of $\mathrm{C}$ concentration, the concentration of $B$ decreased rapidly within the width at about $5 \mathrm{~nm}$ from the central GB toward the matrix.

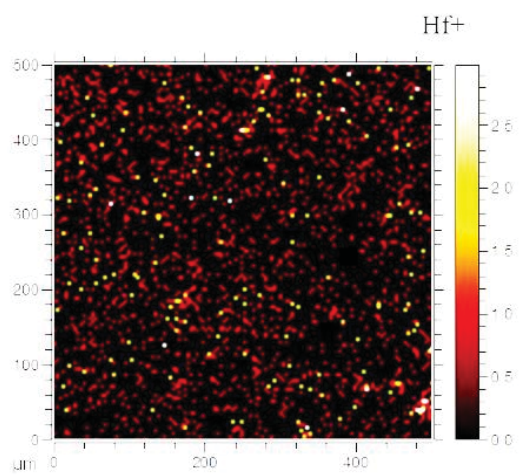

(a)

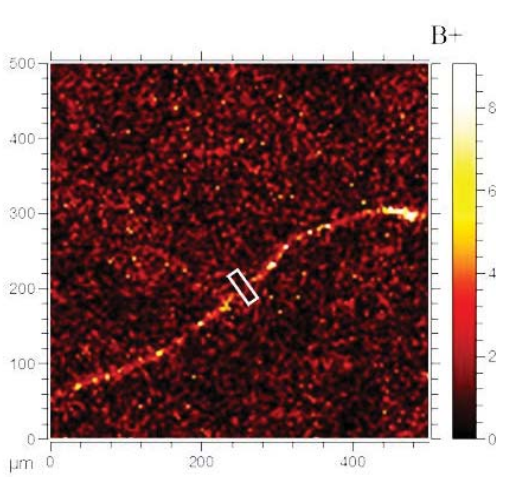

(b)

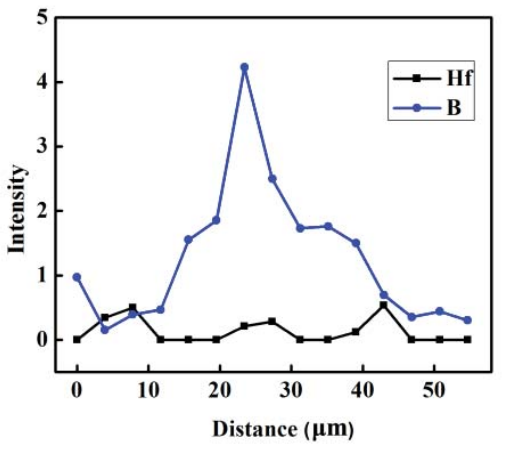

(c)

Fig. 8 TOF SIMS distribution maps of Hf and B near the GB regions in alloy HfB with HAB after full heat treatment: (a) Hf; (b) B; and (c) the corresponding intensity profile of $\mathrm{Hf}$ and $\mathrm{B}$ across the area marked with a white frame in (b).

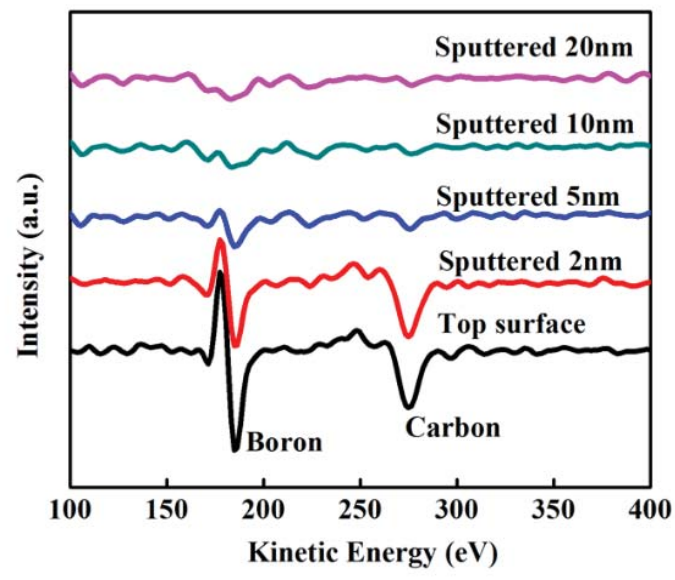

(a)

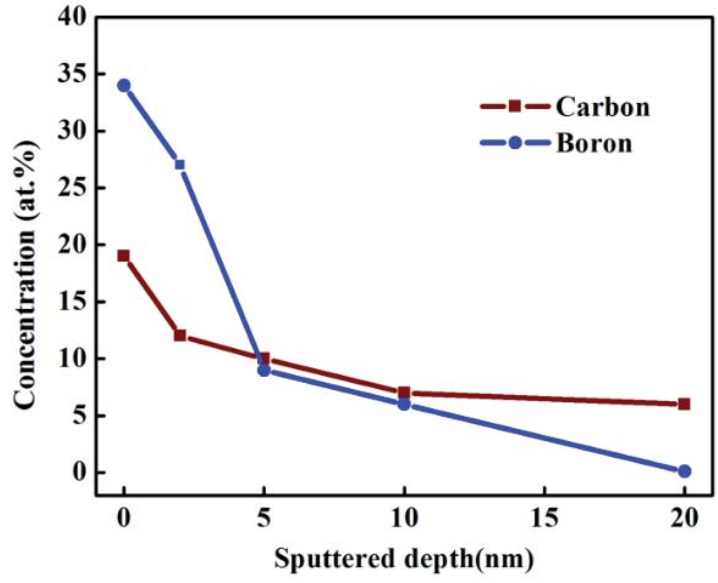

(b)

Fig. 9 Auger spectrum with different sputtered depth on HAB of alloy HfB after full heat treatment (a) and the corresponding concentrations of $\mathrm{B}$ and $\mathrm{C}$ as a function of the sputtered depth (b). 

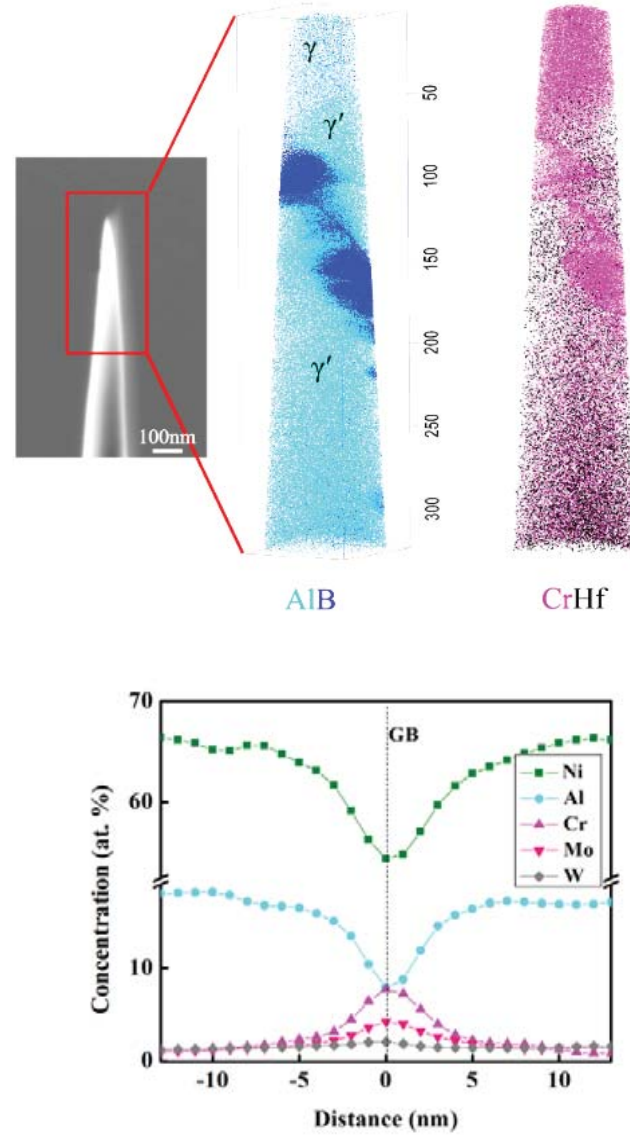

(b)
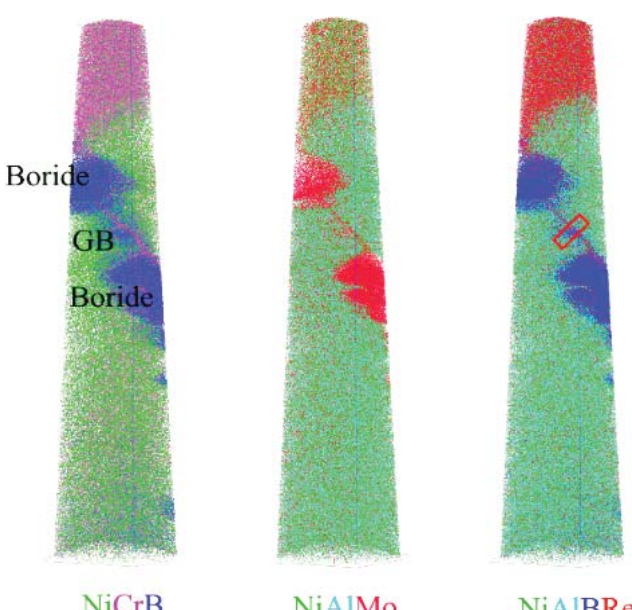

NiAlMo

NiAlBRe

(a)

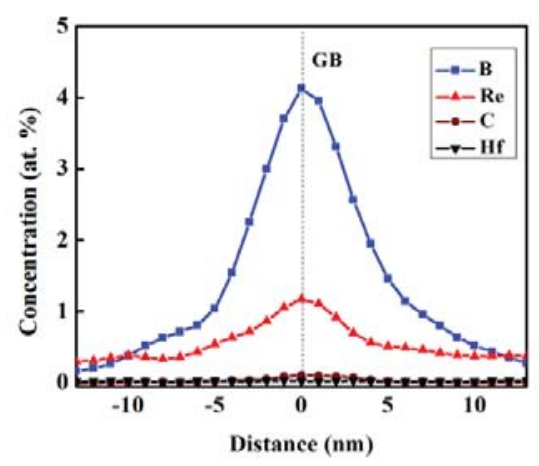

(c)

Fig. 10 APT reconstruction, containing $4 \times 10^{6}$ atoms, and elemental distributions at the HAB of alloy HfB after full heat treatment (a); concentration profiles of alloying elements $\mathrm{Ni}, \mathrm{Al}, \mathrm{Cr}, \mathrm{Mo}, \mathrm{W}$ (b) and $\mathrm{B}, \mathrm{Re}, \mathrm{C}, \mathrm{Hf}$ (c) across the GB in the APT reconstruction in (a).

TOF SIMS and AES techniques provided details of the segregation of $\mathrm{B}$ and $\mathrm{Hf}$ across the region at the micron scale away from the GB, but did not resolve the fine atomic-scale segregation to the interfaces along the GB. In order to verify the segregation behaviors of alloying elements to the GB, APT was performed on HABs in alloy HfB. Fig. 10a is the representative atom probe reconstruction of the $\mathrm{HAB}$ area with 40 million atoms in alloy $\mathrm{HfB}$, from which information about the composition of individual $\gamma^{\prime}$ phase and borides could be extracted. The boride was found to be enriched in $\mathrm{Cr}$ and Mo again. Onedimensional (1D) composition profile across the GB using an analysis box with its z-axis parallel to the GB normal are shown in Figs. 10b and 10c. An enrichment of B, Cr, Mo, C and Re at the GB within the width of approximately $10 \mathrm{~nm}$ was observed. It is interesting to note that the ratios of $\mathrm{B}, \mathrm{Cr}, \mathrm{Mo}, \mathrm{C}$ and $\mathrm{Re}$ concentrations at GB and matrix were 36.9, 5.1, 2.8, 8.3 and 3.3, respectively. No enrichment of $\mathrm{Hf}$ and $\mathrm{W}$ at the GB was observed by atom probe tomography, meanwhile, $\mathrm{Ni}$ and $\mathrm{Al}$ depletion was observed at the GB.

Through the combined analysis of TOF SIMS, AES and APT, a strong B-enriched zone of approximately $10 \mathrm{~nm}$ has been accurately detected at the HAB of alloy HfB. Meanwhile, the relatively weak segregation of $\mathrm{C}$ was also found at the GB. However, no enrichment of $\mathrm{Hf}$ at the GB was observed.

\section{Discussion}

\section{$\underline{\text { 1. Effect of GB misorientation on creep properties }}$}

It is well known that GBs serve as obstacles to dislocation movement, creating dislocation pileups in the vicinity of grain boundaries [2]. Following the analyses of the Read-Shockley theory [10], the GB energy increases as the increase of misorientation in the range of 0 and $25^{\circ}$, thus the cohesive strength between the grains decreases [11]. In this study, it is apparent that the creep rupture lives decreased with increasing GB misorientation for all three bicrystal alloys (Fig. 3). To simplify the analyses, only the base alloy was used here as an example to illustrate the role of GB misorientation in creep rupture properties. The trans-granular failure was observed in the base alloy with LAB (Fig. 5a) and the damage in the form of small cracks initiated at the GB was rarely observed in creepinterrupted tests (Fig. 6a). It is thus evident that dislocations should slide across the LAB, and highly compatible deformation was achieved across the LAB. As a result, excellent creep properties were achieved in the base alloy with the LAB. However, the intergranular fracture was observed in the base alloy with the HAB and the continuous cracks along the GB propagated during the creep-interrupted test (Fig. 6b). Dislocations could not pass through the HAB by sliding or climbing, and the stress concentrated on the GB because of 
dislocation pile-ups. Consequently, the creep rupture life was less than $15 \mathrm{~h}$ due to high GB energy and weak GB strength.

\section{Effect of Hf and B on creep properties of bicrystal alloys with $\underline{\mathrm{LABS}}$}

Fig. 3 shows that the creep rupture lives of bicrystal superalloys with the $\mathrm{LAB}$ reached the maximum by $\mathrm{Hf}$ addition and the minimum by $\mathrm{Hf}$ and $\mathrm{B}$ additions together among three experimental alloys at high temperature $\left(1100{ }^{\circ} \mathrm{C}\right.$ and $\left.980{ }^{\circ} \mathrm{C}\right)$. However, at $760{ }^{\circ} \mathrm{C}$, the creep rupture life was improved in alloy $\mathrm{Hf}$ and it was improved to a higher degree in alloy HfB. As mentioned above, the existence of the LAB has no obvious influence on the creep properties. However, minor addition of Hf resulted in the enhancement of high temperature creep life of SX superalloy DD11 due to higher partitioning ratio of Re in alloy $\mathrm{Hf}$ in our previous study [8]. While minor additions of Hf and B together degraded high temperature creep properties in SX superalloy DD11 due to the existence of residual eutectics in the interdendritic region [12]. The current results suggest that creep rupture lives in three bicrystal alloys with the LAB have the similar trend to those of SX alloys at $980{ }^{\circ} \mathrm{C}$ and $1100{ }^{\circ} \mathrm{C}$ (Figs. $3 \mathrm{a}, 3 \mathrm{~b}$ and $3 \mathrm{~d}$ ). In addition, it should be noted that the creep rupture life in alloy $\mathrm{HfB}$ with $\mathrm{LAB}$ was significantly longer than that of base alloy at $760{ }^{\circ} \mathrm{C} / 785 \mathrm{MPa}$ (Fig. 3c). The GB strengthening mechanism of creep at intermediate temperature is different from that at high temperature, and some related studies of the mechanism during creep at this temperature are still underway.

\section{Effect of Hf and B on creep properties of bicrystal alloys with $\underline{\text { HABs }}$}

There were almost no secondary precipitates along the LABs in all three alloys, but secondary precipitates along the HABs exhibited different morphologies and showed significant effect on creep performance. In this paper, microstructural analyses were conducted including the type and morphology of secondary precipitates along the HAB as well as the elemental segregation. Various microstructural evolutions due to $\mathrm{Hf}$ and $\mathrm{B}$ additions as well as the creep properties are discussed on the basis of quantitative characterizations of microstructures and alloying elemental segregation.

\subsection{Effect of $\mathrm{M}_{3} \mathrm{~B}_{2}$ borides and MC carbides along the HABs}

Carbides were always found to precipitate along the GB, due to the assistance of GB diffusion [13]. Hf is a strong MC carbide forming element, and can control the type and morphology of carbides along the GB in cast superalloys. Chen et al. [7] found that minor grain boundary strengthening elements $(\mathrm{C}, \mathrm{Hf}$ and $\mathrm{B})$ promoted the formation of $\mathrm{MC}$ and $\mathrm{M}_{23} \mathrm{C}_{6}$ carbides, enhancing the creep performance of bicrystal superalloys through inhibiting grain boundary sliding. In this study, it is confirmed that $\mathrm{C}$ segregated to the GB through AES and APT analyses, and formed HfC along the GB (Fig. 4c). There was limited quantity of discontinuous blocky MC carbides enriched in $\mathrm{Hf}$ and $\mathrm{Ta}$ along the $\mathrm{HAB}$ in alloy $\mathrm{Hf}$. The precipitation of $\mathrm{MC}$ carbides along the GB during creep process was not observed after the creep-interrupted test (Fig. 6c). Thus, the improvement of creep properties by $\mathrm{Hf}$ addition was not achieved, especially under high temperature conditions.
The precipitation of $\mathrm{GB}$ borides, including $\mathrm{M}_{3} \mathrm{~B}_{2}$ and $\mathrm{M}_{5} \mathrm{~B}_{3}$, also has significant influence in Ni-base superalloys [14]. Wang et al. [14] found that the applied tensile stress promotes the diffusion of $\mathrm{B}$ atoms, and resulted in the precipitation of many nano-size $\mathrm{M}_{5} \mathrm{~B}_{3}$ borides at $\mathrm{GB}$ during high temperature creep. Generally, the presence of fine and discrete borides along the GB prevents boundary migration and contributes to creep resistance [13]. In this study, the B segregation was confirmed by TOF SIMS, AES and APT, meanwhile, the $\mathrm{Cr}$, Mo and Re existed on the GB through the analyses of APT. As a result, borides can be formed by their reaction with $\mathrm{B}$ directly. Under the condition of $1100{ }^{\circ} \mathrm{C} / 130 \mathrm{MPa}$, the precipitation of initial fine and discrete borides along the GB after the full heat treatment (Fig. 4d) should prevent GB sliding at the beginning of creep deformation. The thermal exposure simulation experiments performed at $1100{ }^{\circ} \mathrm{C}$ without the applied creep stress also suggested that borides precipitated along the HAB in alloy HfB during thermal exposure. And the linear density of GB precipitates increased more significantly for the first $200 \mathrm{~h}$. Meanwhile, a complete GB decorated with fine and discrete $\mathrm{M}_{3} \mathrm{~B}_{2}$ borides appeared in alloy $\mathrm{HfB}$ with $\mathrm{HAB}$ after the creep test interrupted at $40 \mathrm{~h}$ (Fig. 6d). The density of GB precipitates in alloy HfB was about 55\% (Fig. $6 \mathrm{~d}$ ), which was slightly higher than that of GB precipitates after thermal exposure of $200 \mathrm{~h}$. It is indicated that the applied stress obviously promoted the precipitation of borides along the GB at $1100{ }^{\circ} \mathrm{C}$. The precipitation of fine and discrete borides along the GB during creep process should also enhance the creep performance in alloy $\mathrm{HfB}$ through preventing GB migration effectively. As a result, the creep rupture life was significantly improved in alloy HfB with the HAB, compared with the creep property of alloy Hf.

\section{$\underline{3.2 \text { Effect of elemental segregation }}$}

It is well known that the B segregation is beneficial in enhancing the GB cohesion and suppressing intergranular fracture in many metallic and intermetallic alloys [15]. However, at this stage, it is not clear whether the improved GB strength can be ascribed to B being segregated along the grain boundaries or alternatively incorporated into borides in superalloys [16]. Meanwhile, whether the element Hf segregated to the GB has still not been reported in superalloys. In this study, there was no obvious segregation of $\mathrm{Hf}$, but the segregation of $\mathrm{B}$ to the $\mathrm{HAB}$ was confirmed by the analyses of TOF SIMS, AES and APT. And B was also present in the form of borides by these analyses.

GB segregation and its associated Gibbsian interfacial excess of alloying elements are important for understanding GB properties and physical behavior. The Gibbsian interfacial excess of an element $i, \Gamma i$, is defined by the excess number of solute atoms $i$ $\left(N_{i}{ }^{\text {excess }}\right)$ per unit area $A . \Gamma_{i}$ can be calculated for an arbitrary interface using a proxigram and is defined by [17]:

$$
\Gamma i=N_{i}^{\text {excess }} / A=\rho \Delta x \sum_{j=1}^{p}\left(C_{i}^{j}-C_{i}^{m}\right)
$$

where $\rho$ is the atomic density ( 84.06 atoms $\mathrm{nm}^{-3}$ for $\gamma^{\prime}$ phase by analyses of APT in this work); $\Delta x$ is the distance between the players in the proxigram; and $C_{i}^{m}$ is the average concentration of element $i$ in the matrix. When applying the Gibbs adsorption isotherm [18] at $1100{ }^{\circ} \mathrm{C}$ :

$$
\Delta \sigma_{i}=-\Gamma_{i} k_{b} T \ln \left(\frac{C_{i}^{G B}}{C_{i}^{\text {Matrix }}}\right)
$$


where $\Delta \sigma_{i}$ is the reduction interfacial free energy of an element $i$; $k_{b}$ is the Boltzmann constant; $T$ is the temperature; $C_{i}{ }^{\text {Matrix }}$ is the average concentration of element $i$ in the matrix and $C_{i}^{G B}$ is the concentration of element $i$ at the GB.

Table III. Atomic concentrations of solute atoms at the matrix and grain boundary, and the reduction of interfacial free energy due to solute segregation of alloying elements at the HAB of alloy HfB after the full heat treatment

\begin{tabular}{|c|c|c|c|}
\hline Element & $\begin{array}{c}C_{i}^{\text {Matrix }} \\
(\text { at.\%) }\end{array}$ & $\begin{array}{c}C_{i}^{G B} \\
(\text { at.\% })\end{array}$ & $\begin{array}{c}\Delta \sigma_{i} \\
\left(\mathrm{~mJ} \mathrm{~m}^{-2}\right)\end{array}$ \\
\hline $\mathrm{Ni}$ & 66.14 & 54.40 & -9.22 \\
\hline $\mathrm{Al}$ & 17.47 & 7.90 & -21.86 \\
\hline $\mathrm{W}$ & 1.20 & 2.06 & -0.45 \\
\hline $\mathrm{Re}$ & 0.36 & 1.18 & -0.93 \\
\hline $\mathrm{Cr}$ & 1.20 & 6.10 & -10.29 \\
\hline $\mathrm{Mo}$ & 1.50 & 4.23 & -2.23 \\
\hline $\mathrm{B}$ & 0.11 & 4.07 & -79.59 \\
\hline $\mathrm{C}$ & 0.01 & 0.08 & -0.22 \\
\hline $\mathrm{Hf}$ & 0.02 & 0.03 & -0.01 \\
\hline $\mathrm{Nb}$ & 0.42 & 0.35 & 0.10 \\
\hline $\mathrm{Co}$ & 9.44 & 15.28 & -1.94 \\
\hline $\mathrm{Ta}$ & 2.01 & 1.03 & -0.71 \\
\hline $\mathrm{Total}$ & & & -127.34 \\
\hline
\end{tabular}

The reduction of interfacial free energy due to solute segregation of alloying elements at the HAB in alloy HfB was calculated via means of the measured ratios by APT. The atomic concentrations of solute atoms at the matrix and grain boundary, and the reduction of the interfacial free energy are summarized in Table III. The total reduction of the interfacial free energy due to the segregation of alloying elements was $127.34 \mathrm{~mJ} \mathrm{~m}^{-2}$ at $1100{ }^{\circ} \mathrm{C}$ in alloy HfB. It should be noted that the reduction of the interfacial free energy due to solute segregation of $\mathrm{B}$ at this GB was $79.59 \mathrm{~mJ} \mathrm{~m}^{-2}$, which was significantly higher than those of other alloying elements.

Therefore, it is suggested that the B segregation to the HAB in alloy HfB enhanced the GB cohesion through the reduction of interfacial free energy, thereby playing an important role in changing the fracture mode from completely intergranular in the base alloy and alloy Hf to mixed inter- and trans-granular failure in the alloy HfB. In other words, the enhancement of the GB cohesion by $\mathrm{B}$ segregation should play an important role in improving the properties of alloy HfB with the HAB.

\section{$\underline{3.3 \text { Cellular recrystallization along the } \mathrm{HAB}}$}

Cellular recrystallization is one type of microstructural instability of grain boundaries, and it transforms $\gamma-\gamma^{\prime}$ two-phase microstructure into $\gamma-\gamma^{\prime}+$ TCP lamellar structure in Ni-based superalloys. Grain boundary misorientation had significant effects on grain boundary energy and migration [19]. Yu et al. reported that the cellular structure existed along $25^{\circ}$ boundary after heat treatment at $1100{ }^{\circ} \mathrm{C}$ for $50 \mathrm{~h}$ along the bonded boundaries of the same SX superalloy containing $5 \mathrm{wt} . \%$ Re [19]. Nystrom et al. reported that cellular discontinuous precipitation occurred at grain boundaries with the misorientation higher than $10^{\circ}$ at $1093{ }^{\circ} \mathrm{C}$ in a bicrystal superalloy containing $6.7 \mathrm{wt} . \% \mathrm{Re}$ [20]. The current results clearly suggest that localized precipitation of cellular recrystallization occurred along the grain boundary with a misorientation angle about $20^{\circ}$ in the base alloy containing 3 wt.\% Re due to high GB energy and diffusion mobility of refractory alloying elements. This phenomenon is identical to the reports of $\mathrm{Yu}$ et al [19] and Nystrom et al. [20]. Cellular recrystallization can also serve as origins of crack initiation and propagation by de-cohesion of precipitates/large $\gamma^{\prime}$ phase of the cellular recrystallized microstructure along the GB (Fig. 6b), and significantly degraded the creep performance of the base alloy. Nevertheless, in this study, the cellular recrystallization along GB was suppressed in both alloys Hf and HfB. Limited studies indicated that cellular recrystallization was linked to the interface energy and defect enthalpy in superalloys with a fixed GB misorientation [21]. In the current study, there was no obvious segregation of $\mathrm{Hf}$ and the reduction of GB interface energy by the addition of $\mathrm{Hf}$ was not significant (Table III). But the reduction of GB interfacial energy by the addition of B may be beneficial for the suppression of cellular recrystallization. However, the key mechanism of suppressing the cellular recrystallization by additions of $\mathrm{Hf}$ and $\mathrm{B}$ still remains unclear and the related investigations are still underway.

\section{Conclusions}

The influence of minor alloying elements (Hf and B) and misorientations $\left(5^{\circ}\right.$ and $\left.20^{\circ}\right)$ on microstructural evolution, segregation behaviors of alloying elements as well as transverse and longitudinal creep properties were investigated in the current study. The following conclusions can be drawn:

1. For a fixed alloy, the creep rupture lives of bicrystal superalloy with the HAB were significantly less than those with the LAB. The additions of $\mathrm{Hf}$ and $\mathrm{B}$ together significantly improved the transverse and longitudinal creep rupture lives with the $\mathrm{HAB}$ under the conditions of $1100{ }^{\circ} \mathrm{C} / 130 \mathrm{MPa}, 980{ }^{\circ} \mathrm{C} / 250 \mathrm{MPa}$ and $760{ }^{\circ} \mathrm{C} / 785 \mathrm{MPa}$.

2. Transgranular failure was observed in all three alloys with the LAB and completely intergranular failure was observed in B-free alloys with the HAB. However, the mixed interand trans-granular failure was achieved in the B-doped alloy with the HAB.

3. A strong B-enriched zone of approximately $10 \mathrm{~nm}$ has been detected at the $\mathrm{HAB}$ of the alloy contained $\mathrm{Hf}$ and $\mathrm{B}$ after heat treatment. However, no enrichment of $\mathrm{Hf}$ at the GB was detected. Meanwhile, the segregation of $\mathrm{C}, \mathrm{Cr}, \mathrm{Re}$ and Mo was also found at the GB in the descending order.

4. The cellular recrystallization microstructure along the HAB was found in the base alloy after the full heat treatment, but this was significantly suppressed with either Hf or a joint addition of $\mathrm{Hf}$ and $\mathrm{B}$.

5. The precipitation of fine and discrete borides along the GB during creep process enhanced the creep performance in the alloy contained $\mathrm{Hf}$ and $\mathrm{B}$ with the $\mathrm{HAB}$ through preventing GB migration effectively. Meanwhile, the reduction of GB energy by the segregation of $\mathrm{B}$ may also play the role in improving the creep properties in alloy HfB with the HAB. 
The current study presents that minor $\mathrm{Hf}$ and $\mathrm{B}$ additions can provide more damage resistance for misoriented grain boundaries up to $20^{\circ}$ in DD11 single crystal superalloys, suggesting that the tolerance of GB misorientation defects in aeroengine blades may be significantly improved by minor alloying additions, compared with previous studies [4-6]. Moreover, the combined additions of $\mathrm{Hf}$ and $\mathrm{B}$ may be helpful for breaking the technical and economic barriers in transitioning single crystal technology to large industrial gas turbine (IGT) components.

\section{Acknowledgments}

The authors are grateful to Y. R. Zheng, S. Tin, W. Y. Yang, and B. H. Ge for useful discussions. The financial support provided by National High Technology Research and Development Program (No. 2012AA03A513) and National Basic Research Program of China (No. 2010CB631201).

\section{References}

1. T.M. Pollock and S. Tin, "Nickel-Based Superalloys for Advanced Turbine Engines: Chemistry, Microstructure, and Properties," Journal of Propulsion and Power, 22, (2006), 361374.

2. R.C. Reed, The Superalloys: Fundamentals and Applications (New York: Cambridge University Press, 2006).

3. J.R. Li, J.Q. Zhao, S.Z. Liu, M. Han. "Effects of Low Angle Boundaries on the Mechanical Properties of Single Crystal Superalloy DD6," Superalloys 2008, eds. R.C. Reed et al. (Warrendale, PA: The Minerals, Metals and Materials Society, 2008), 443-451.

4. E.W. Ross and K.S. O'Hara, "Rene' N4: A First Generation Single Crystal Turbine Airfoil Alloy with Improved Oxidation Resistance Low Angle Boundary Strength," Superalloys 1996, eds. R.D. Kissinger et al. (Warrendale, PA: The Minerals, Metals and Materials Society, 1996), 19-25.

5. K. Harris and J.B. Wahl, "Improved Single Crystal Superalloys. CMSX-4®(SLS) $[\mathrm{La}+\mathrm{Y}]$ and CMSX-486®," Superalloys 2004, eds. K.A. Green, et al. (Warrendale, PA: The Minerals, Metals and Materials Society, 2004), 45-52.

6. D.M. Shah, A. Cetel. "Evaluation of PWA1483 for Large Single Crystal IGT Blade Applications," Superalloys 2000, eds. T.M. Pollock et al. (Warrendale, PA: The Minerals, Metals and Materials Society, 2000), 295-304.

7. Q.Z. Chen, C.N. Jones, and D.M. Knowles, "The Grain Boundary Microstructures of the Base and Modified RR2072 Bicrystal Superalloys and Their Effects on the Creep Properties," Materials Science and Engineering A, 385, (2004), 402-418.

8. Y.S. Zhao, J. Zhang, Y.S. Luo, D.Z. Tang, Q. Feng, "Effects of $\mathrm{Hf}$ on High Temperature Low Stress Rupture Properties of a Second Generation Ni-Based Single Crystal Superalloy DD11," Acta Metallurgica Sinica, 51, (2015), 1261-1272.

9. B.P. Geiser, D.J. Larson, E. Oltman, S. Gerstl, D. Reinhard, T.F. Kelly, T.J. Prosa. "Wide-Field-of-View Atom Probe
Reconstruction," Microscopy \& Microanalysis, 15, (2009) 292 293.

10. M.D. Sangid, H. Sehitoglu, H.J. Maier, T. Niendorf, "Grain Boundary Characterization and Energetics of Superalloys," Materials Science and Engineering: A, 527, (2010), 7115-7125.

11. P. Peralta, C. Laird, "The Role of Strain Compatibility in the Cyclic Deformation of Copper Bicrystals," Acta Materialia, 45, (1997), 3029-3046.

12. Y.S. Zhao, J. Zhang, Y.S. Luo, D.Z. Tang. "Effects of Hf and B on High Temperature Low Stress Creep Behavior of a Second Generation Ni-based Single Crystal Superalloy DD11," Materials Science and Engineering: A, in press.

13. L.Z. He, Q. Zheng, X.F. Sun, H.R. Guan, Z.Q. Hu, A.K. Tieu, C. Lu, H.T. Zhu, "Effect of Carbides on the Creep Properties of a Ni-base Superalloy M963," Materials Science and Engineering: A, 397, (2005), 297-304.

14. D. Wang, C. Liu, J. Zhang, L. Lou. "Evolution of Grain Boundary Precipitates in a Directionally Solidified Ni-base Superalloy During High Temperature Creep," Superalloys 2012, eds. M. Bensch et al. (Warrendale, PA: The Minerals, Metals and Materials Society, 2012), 363-368.

15. J.H. Luan, Z.B. Jiao, L. Heatherly, E.P. George, G. Chen, C.T. Liu, "Effects of Boron on the fracture behavior and ductility of cast Ti-6Al-4V alloys," Scripta Materialia, 100, (2015), 90-93.

16. P. Kontis, H.M. Yusof, S. Pedrazzini, M. Danaie, K. Moore, P. Bagot, M. Moody, C. Grovenor, R. Reed, "On the Effect of Boron on Grain Boundary Character in a New Polycrystalline Superalloy," Acta Materialia, 103, (2016), 688-699.

17. O.C. Hellman, D.N. Seidman, "Measurement of the Gibbsian Interfacial Excess of Solute at an Interface of Arbitrary Geometry Using Three-dimensional Atom Probe Microscopy," Materials Science and Engineering: A, 327, (2002), 24-28.

18. D. Isheim, M.S. Gagliano, M.E. Fine, D.N. Seidman, "Interfacial Segregation at Cu-rich Precipitates in a High-strength Low-carbon Steel Studied on a Sub-nanometer Scale," Acta Materialia, 54, (2006), 841-849.

19. Z.R. Yu, X.F. Ding, Y.R. Zheng, L.M. Cao, Q. Feng. Misorientation Effect of Grain Boundary on the Formation of Discontinuous Precipitation in Second and Third Generation Single Crystal Superalloys. MATEC Web of Conferences, 2014, 11006-11012.

20. J.D. Nystrom, T.M. Pollock, W.H. Murphy, A. Garg, "Discontinuous Cellular Precipitation in a High-refractory Nickel-base Superalloy," Metallurgical and Materials Transactions A, 28, (1997), 2443-2452.

21. A. Heckl, S. Cenanovic, M. Göken, R.F. Singer, "Discontinuous Precipitation and Phase Stability in Re- and RuContaining Nickel-Base Superalloys," Metallurgical and Materials Transactions A, 43, (2012), 10-19. 